\title{
NUMERICAL STUDY OF CIRCULATION ON THE INNER AMAZON SHELF
}

\author{
Roberto Fioravanti Carelli Fontes ${ }^{1}$, Belmiro Mendes Castro ${ }^{2}$, Robert C. Beardsley ${ }^{3}$ \\ 1 Universidade Estadual Paulista \\ 2 Instituto Oceanográfico da Universidade de São Paulo \\ 3 Woods Hole Oceanographic Institution
}

Received: date / Revised version: 02/Jun/2008

\begin{abstract}
We studied the circulation on the coastal domain of the Amazon Shelf by applying the hydrodynamic module of the Estuarine and Coastal Ocean Model and Sediment Transport - ECOMSED. The first barotropic experiment aimed to explain the major bathymetric effects on tides and those generated by anisotropy in sediment distribution. We analyzed the continental shelf response of barotropic tides under realistic bottom stress parametrization $\left(C_{d}\right)$, considering sediment granulometry obtained from a faciologic map, where river mud deposits and reworked sediments areas are well distinguished, among others classes of sediments. Very low $C_{d}$ values were set in the fluid mud regions off the Amapá coast $\left(1.010^{-4}\right)$, in contrast to values around $3.510^{-3}$ for coarser sediment regions off the Pará coast. Threedimensional experiments represented the Amazon River discharge and trade winds, combined to barotropic tide influences and induced vertical mixing. The quasi-resonant response of the Amazon Shelf to the $\mathrm{M}_{2}$ tide act on the local hydrodynamics by increasing tidal admittance, along with tidal forcing at the shelf break and extensive fluid mud regions. Harmonic analysis of modeled currents agreed well with analysis of the AMASSEDS observational data set. Tidal-induced vertical shear provided strong homogenization of threshold waters, which are subject to a kind of hydraulic control due to the topographic steepness. Ahead of the hydraulic jump, the low-salinity plume is disconnected from the bottom and acquires negative vorticity, turning southeastward. Tides act as a generator mechanism and topography, via hydraulic control, as a maintainer mechanism for the lowsalinity frontal zone positioning. Tidally induced southeastward plume fate is overwhelmed by northwestward trade winds so that, along with background circulation, probably play the most important role on the plume fate and variability over the Amazon Shelf.
\end{abstract}

Send offprint requests to:

\section{Introduction}

The Amazon Shelf (AS) still is a relatively low impacted environment where physical phenomena are free of anthropogenic influences, making this region a unique natural laboratory on Earth. Located near the equator, the AS is subjected to geostrophy degeneration so that equilibrium is achieved by balancing others terms in the horizontal momentum equations. This feature promotes rapidly dynamic responses, compared with other environments were geostrophy is important. The AS is an unique marine environment subject of broad and complex hydrodynamic processes from both, local and remote connections, mostly related to the huge river discharge, the influence of tides, the trade winds and the North Brazil Current (NBC, Figure 1). The NBC is a well-established western boundary current that carries out water northwestward, along the coast of Brazil. Mostly of its influences occur in the outer domain of the AS, transporting mass and heat across the equator, into the Northern Hemisphere (Johns et al. 1990 Geyer et al., 1996; Johns et al. 1998). The coastal environment and the inner portion of the AS are submitted to distinct forces: tides, trade winds and fresh water discharges due to the Amazon and Pará Rivers (AR/PR). Although the huge fresh water discharge produces a sharp haline front, the dynamic processes on the AS are dominated by strong semi-diurnal tidal circulation. Another important dynamic consideration is based on large sediment deposition patches distributed on the AS, which inhibit turbulence and decrease friction in the Bottom Boundary Layer (BBL). Dissipation of total energy is diminished, so currents and sea level were best fit considering some local influences of decreasing friction. Former studies have pointed out the relationship of large sediment patches and energy dissipation on coastal marine environments (Beardsley et al., 1995: Geyer et al. 1996). Gabioux et al. (2005) has successfully applied a barotropic model to study the tidal amplification due to bottom stress adjustment, considering the fluid mud 


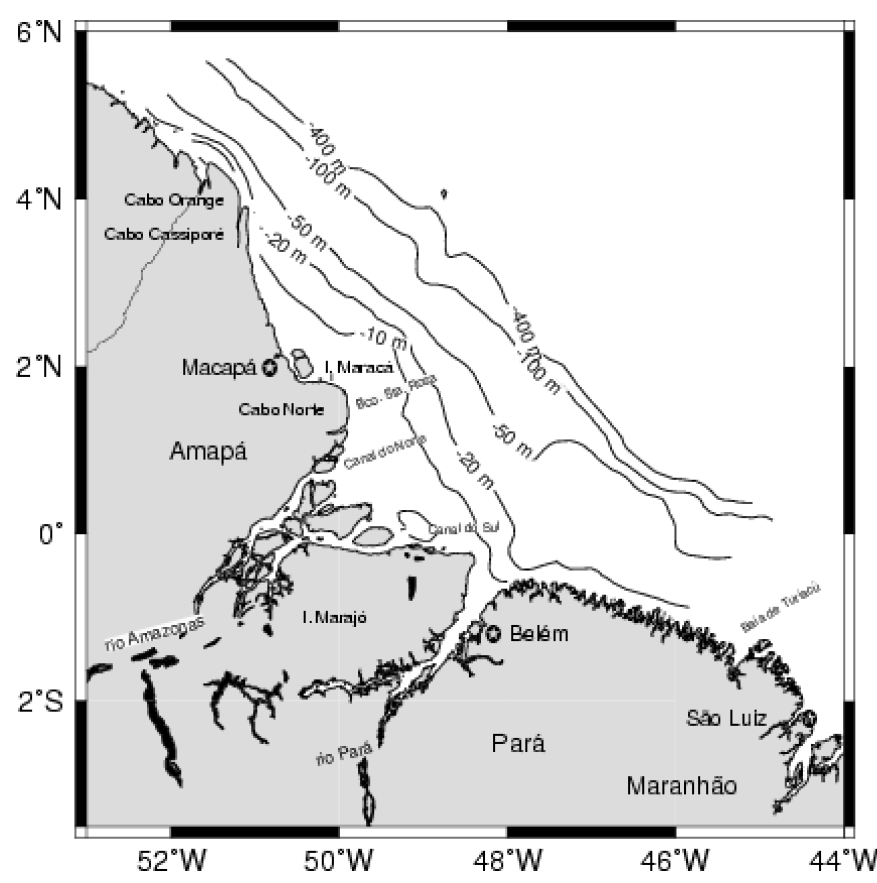

Fig. 1 The Amazon Shelf bathymetry and locations along the North Brazil Coast.

distribution over the shelf. We also reproduced those considerations, relating them to the dynamic aspects on the frontal zone positioning over the inner shelf. The dynamic influences of the wind field variability on the plume fate over the entire AS was first investigated by Paluszkiewicz et al. (1995), by means of numerical modeling. They studied how fast and intense were the responses of the plume drifting to wind field shifting and relaxation conditions, relating them to balance of terms under the equatorial geostrophy degeneration.

In a most recent study, Nikiema et al. (2007) applied a three-dimensional numerical model to study the plume dynamics of the Amazon and Pará Rivers on the AS.The river discharge, the coastal current and influences of the NBC, the trade winds and the tides were progressively introduced in the model, in order to study their influences on the plume horizontal structure. They found that the coastal current, among various prevailing wind conditions, has a major effect on orienting the plume extension northwestward. In this current study we focused on the plume river formation and how tides and the vertical structure of mass, imposed by the river discharge, affect the frontal zone positioning over the inner shelf.

The Amazon River Estuary, due to its characteristics of broad extension and huge discharge, does not fit into a classical definition of estuary, once the mixing zone is not laterally constrained by walls (Miranda et al. , 2002). The haline front develops further ahead from the mouth and preserves much of its characteristics, although embedded in the oceanic domain. The tides act as a progressive wave entering through the Amazon Delta and propagating upriver, reaching up regions as far as 850 $\mathrm{km}$.

Here we present results from numerical modeling of currents, taking into account the complexity of the AS on the river plume fate, its formation and shape as well as the frontal zone positioning. The formation and maintenance of the bottom salinity front can be partially explained by the Hydraulic Control Theory (HCT). One requirement of that theory relies on the consideration of a rigid lid approximation for surface displacements, which is clearly violated on this model where tides are considered, amongst other influences. Details on adaptation of this approach is described in Fontes (2000), based on Cudaback and Jay (1996). Generation, positioning and maintenance of the frontal zone were studied by means of numerical experiments shown in Section 5. The data set employed for model calibration and validation was collected during the Project AMASSEDS AMASSedS, 1990), supporting most of evidences raised in this work.

The NBC and other oceanic processes other than tides have not been included in this study. Although ring formation, rectrofletion and the NBC transport are important oceanographic phenomena related to the AS circulation, this study was focused on the inner portion of the domain. The river discharge, bathymetry and the stirring mechanism induced by tides promote most of the plume genesis definition. Paluszkiewicz et al. (1995) conducted a meso-scale variability study of the Amazon River plume on the AS and verified that variations onto the plume fate are mostly driven by the local wind field rather than other influences.

The model methodology is described in Section 2 , as well as boundary conditions. Section 3 describes the results of tidal modeling on the AS. Plume dynamics and vertical mixing processes on the AS are described in Section 4, considering the tidal effects on the plume fate over the shelf and local wind-driven circulation. Sections 5 deals with the frontal zone positioning over the AS, while Section 6 deals with interactions of the coastal circulation and the river plume. Conclusions are summarized in Section 7 .

\section{Methods}

We applied the hydrodynamic module of the Estuarine and Coastal Ocean Model and Sediment Transport ECOMSED. The development of this model has its origins with the creation of the Princeton Ocean Model POM - (Blumberg and Mellor, 1980, 1987) followed by an upgraded version called ECOM (Blumberg, 1996). The model is based on a three-dimensional set of the Navier-Stokes formulation, extended to the Boussinesq and shallow-water approximations, under consideration of a geophysical fluid. The system of primitive equations consists of the horizontal motion terms, including geostrophic and baroclinic effects. An equation of 
state solves the density, also considering heat and salt exchanges through the free surface, as well as river intakes. The governing equations contain parametrized Reynolds stress and flux terms that account for the turbulent diffusion of momentum, salt and heat. The vertical mixing coefficients were obtained by using the second-order turbulence closure scheme described by Mellor and Yamada (1982).

The horizontal time differencing scheme is explicit whereas the vertical differencing is implicit. The latter eliminates time constraints for the vertical coordinate and permits the use of fine vertical resolution in the surface and bottom boundary layers.

The equations governing the coastal and shelf dynamics resolve propagation of both related gravity waves: fast-moving external and slow-moving internal modes. The model employs the mode splitting technique in order to solve the external and internal modes separately, by defining different time stepping ( $d t$ and $d t i$ respectively).

For the horizontal grid discretization, we used a curvilinear and orthogonal lattice with 13041 size-variable elements and 17 levels on vertical discretization. The vertical coordinate $z$ was re-written under the $\sigma$-coordinate transformation:

$$
\sigma=\frac{z-\eta}{H+\eta}
$$

We applied a telescopic grid so that higher resolution was obtained near the river mouth (western boundary) and coarser resolution was set on the open ocean (eastern boundary). Diagonal grid spacing is about 4 to $8 \mathrm{~km}$ in most of the interested area and 10 to $16 \mathrm{~km}$ away from the river mouth, nearby the open ocean boundaries.

\subsection{Initial and boundary conditions}

In ECOMSED, the bottom friction parametrization follows Grant and Madsen (1986), where the drag coefficient $\left(C_{d}\right)$ can be obtained by adjusting the bottom roughness. This parametrization essentially depends on the characterization of the bed layer:

$$
C_{d}=\frac{\kappa^{2}}{\ln ^{2}\left(z / z_{\circ}\right)}
$$

where $\kappa$ is the von Kármán constant; $z$ is the depth above the bed and $z_{\circ}$ is the roughness length scale.

In a realistic marine environment, $z_{\circ}$ as in Equation 2 should be rewritten as $z_{\text {oc }}$, in order to accommodate other physical, morphological and biologic effects on the bottom roughness (Taylor and Dyer, 1977, Glen and Grant, 1987). Adams and Weatherly (1981) defined a velocity profile based on these considerations,

$$
u(z)=\frac{u_{*}}{\kappa}\left[\log \left(\frac{z}{z_{o c}}\right)+\beta \int_{z_{o c}}^{z} \frac{R i_{H}}{z} d z\right]
$$

where $R i_{H}$ is the Richardson's Number defined by Heathershaw (1979),

$$
R i_{H}=\frac{w_{s} \kappa z g c}{\rho u_{*}^{3}}\left(1-\rho / \rho_{s}\right)
$$

where,

$w_{s}$ : sediment settling velocity;

$c$ : concentration of sediments;

$\rho_{s}$ : density of sediments;

$\kappa$ : von Kármán's constant.

The bottom stress $\left(C_{d}=u_{*}^{2} / u^{2}\right)$ can be obtained from Equation 3 .

$$
C_{d} \approx \frac{\kappa^{2}}{\left[\left(1+4.7<R i_{H}>\right) \log \left(\frac{z}{z_{\circ c}}\right)\right]^{2}}
$$

where $<R i_{H}>$ represents the vertical integrated Richardson's Number.

In the bottom boundary layer, we prescribed the drag coefficient directly from sediment distribution, instead applying the original model formulation. From Dyer (1986) we were able to relate a wide range of sediment classes with bottom roughness, considering a low stratified fluid into the BBL. We set this bottom stress formulation by compilation of sediment distribution over the AS (Figure 2) and definition of fluid mud distributions obtained during the AMASSEDS. Figure 3, shows the results of that formulation, considering the sediment class and fluid mud distributions over the AS. Fluid mud regions have lowest $C_{d}$ values while mud- and sand-mixtures assume intermediate values.

The river inflow was prescribed by elevation of the sea surface at the river boundary grid points connecting the interior computational domain. We defined river discharge salinity and temperature according to values measured during AMASSEDS, as seen in Table 1. The elevation boundary condition formulation through the river mouth allowed outcome tidal waves to propagate out freely.

At the northeastern open boundary we prescribed tidal elevation data based on a global tidal model (Eanes and Bettadpur, 1995). The boundary condition formulation was modified from an absolute clamped condition, $\eta=$ $\eta_{d a t a}$, to a partially clamped condition:

$$
\frac{\partial \eta}{\partial t}+c \frac{\partial \eta}{\partial x}=\frac{\eta-\eta_{d a t a}}{T L A G}
$$

where $\eta$ is the sea surface elevation above some reference level computed by the model and $\eta_{\text {data }}$ is the elevation specified from the global tidal model.

This is a partially clamped water level boundary condition formulation, as in Mellor and Kantha (1985). It allows some prescribed waves, as tides, to enter the domain, as well as a means of radiating out undesirable long-waves generated at the interior of the domain. The 


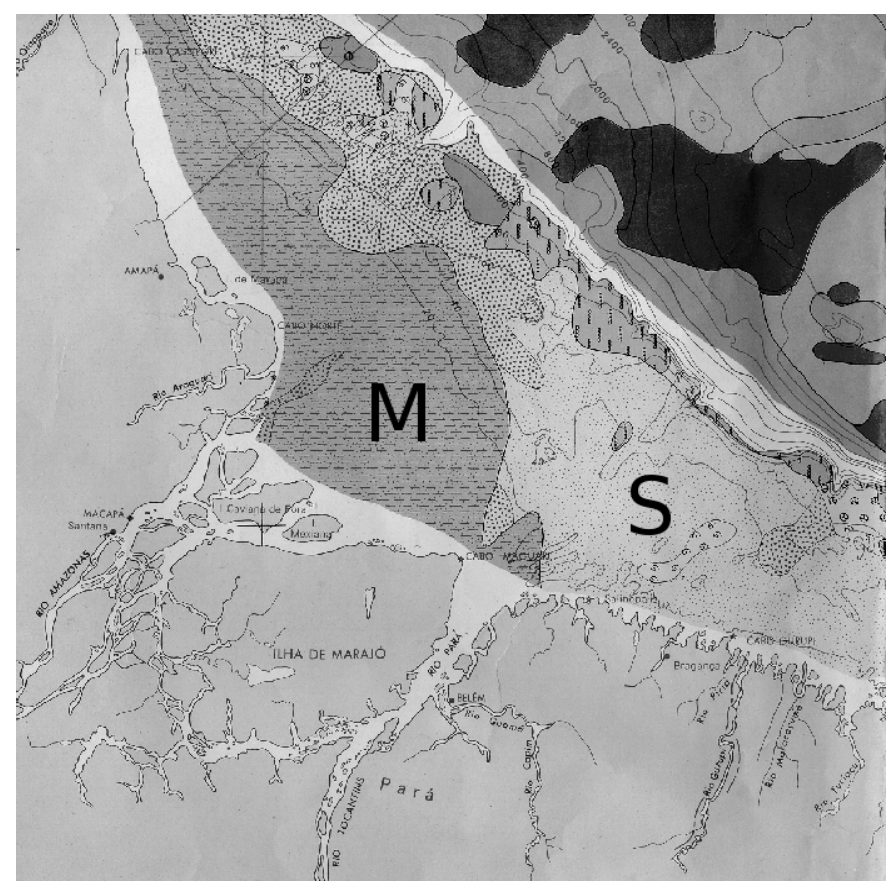

Fig. 2 Faciologic map of the Amazon Shelf from BRASIL (1979). Mud (M) and sand (S) sediment patches are annotated in the figure, representing regions of extreme $C_{d}$ parametrization.

parameter $T L A G$ is the time scale, considering propagation of long-waves throughout the computational domain with phase velocity $c=\sqrt{g H}$. This parameter was obtained by estimation of value superior to the period of the $M_{2}$ tidal component. TLAG was set considerable higher at the others open boundaries (northwestern and southeastern), so the scheme approached a radiation condition.

For salinity and temperature, we applied an open boundary condition under relaxation, described by a sponge layer formulation. The transitional state for both temperature and salinity fields was made by applying a dumping coefficient $\gamma_{i}$, which depended on the grid index position into the sponge layer and its orientation. It varied according to the hyperbolic function (for the northeastern boundary): 


$$
\begin{array}{r}
\gamma_{i}(i s p g)=1-\tanh [0.2(i s p g)] \\
V(i s p g, j, k)=\left[\gamma_{i}(i s p g) V(i b n d, j, k)\right]+\left[\left(1-\gamma_{i}\right) V(i s p g, j, k)\right]
\end{array}
$$


Table 1 Temperature, salinity and other environmental data used in the plume spreading experiment.

\begin{tabular}{lr} 
Dynamical Mode & Prognostic \\
\hline run time & $248.4 \mathrm{~h}$ \\
River outflow discharge & $1.9810^{5} \mathrm{~m}^{3} \mathrm{~s}^{-1}$ \\
Salinity discharge & 0.0 \\
Temperature discharge & $25.0^{\circ} \mathrm{C}$ \\
Ambient initial salinity & 35.0 \\
Ambient initial temperature & $25.0^{\circ} \mathrm{C}$ \\
\hline
\end{tabular}

where $i s p g$ is the index of the grid element into the sponge layer and ibnd is located at the northeastern boundary. $i s p g=\{(i b n d-n): i b n d\} . V$ is the considered variable. These conditions where also applied for the northeastern and southwestern open boundaries, where indexes $i$ and $j$ were properly modified to represent the orientation of the sponge layer.

In addition to this formulation, we employed an offshore telescopic grid. Both conditions damped the internal wave boundary reflection, including those not considered by the single selected wave defined in the partial clamped formulation. Besides all those considerations, the northeastern open boundary was placed far from the shelf break, so that the river plume suffered minimum reflective effects.

Salinity and temperature data set used for model implementation came from the AMASSEDS program, as reported by Alessi et al. (1992). Analysis of this data set shows buoyancy is primarily due to salinity variations since temperature was relatively constant over a 30-day record. This feature agrees with the tropical wet climate type designation, where precipitation occurs all year long and monthly temperature variations are less than $3^{\circ} \mathrm{C}$.

\section{Tides on the Amazon Shelf}

Gabioux et al. (2005) applied a two-dimensional model to study the tidal propagation over the AS considering bottom stress parametrization over mud regions. Here we reproduced their results and extended the interpretation of the bottom stress, considering its influences on the baroclinic structure and how tides are related on the maintenance and positioning of the salinity front.

The higher tidal amplitudes observed near Maracá Island (Figure 1) were mostly due to the semi-diurnal tidal harmonic $M_{2}$, with amplitude reaching values as high as $3.5 \mathrm{~m}$. This region is subject to huge amounts of terrigenous material supplied by the Amazon River, forming a thick layer of fluid mud, which plays an important role on damping the bottom shear stress.

Lowest amplitudes were found nearby the Pará Coast, a region characterized by reworked sediments from alluvial deposits that promote an increase in $C_{d}$ parametriza- tion on regions of the continental shelf. The tidal amplification was studied by Beardsley et al. (1995), who employed an analytical model to characterize the nearly resonant nature of this continental shelf. They obtained a width of $258 \mathrm{~km}$, based on the interpretation of a quarter wavelength resonant condition across the continental shelf. The analytical model depends on the ratio of coastal and shelf break elevations and shelf characteristics, including bathymetry and friction timescale.

The AS width varies between 125 and $325 \mathrm{~km}$ and, at some regions, resonance plays the most important role on tidal amplification once its width is close to that resonant value for the $M_{2}$ tidal component. Indeed, tidal admittance is 3.0 near Cabo Norte (North Cape) where the shelf width matches the resonant value.

In order to define a spatially variable distribution of bottom drag coefficient, we combined observed results from AMASSEDS with others obtained from metamorphic faciologic maps (Figure 3). Wind waves do not substantially affect the BBL since in equatorial regions storms are less frequent. Figure 4 shows tidal stations considered in AMASSEDS while Table 2 synthesizes both observed and modeled results.
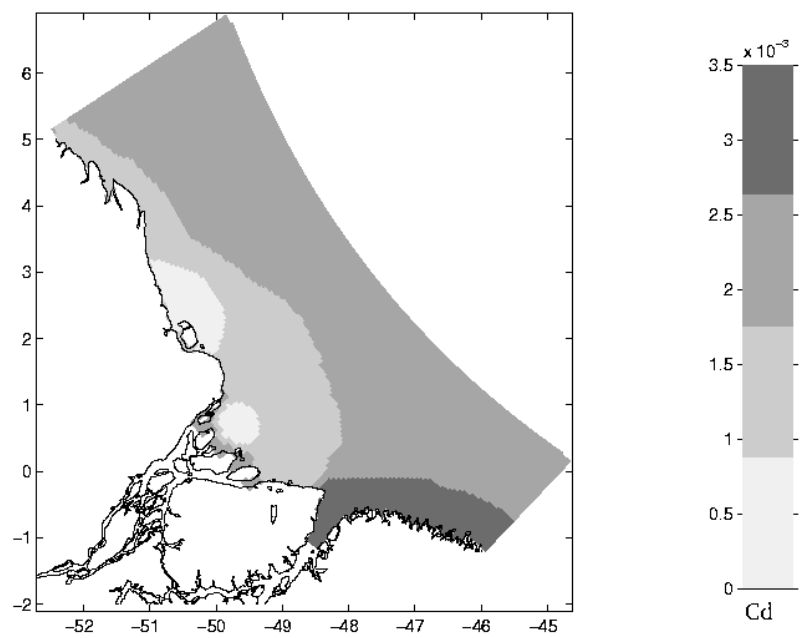

Fig. 3 Spatial distribution of the bottom stress parameter $\left(C_{d}\right)$ on the AS. Values range from $2.010^{-4}$ for fluid mud regions to $3.210^{-3}$ in reworked sediment background distributions.

Regarding characterization of tides over the AS, we found the form ratio number

$$
F=\frac{K_{1}+O_{1}}{M_{2}+S_{2}}=0.13
$$

which defines tides in this region as essentially semidiurnal.

The sea-level boundary conditions for the model semidiurnal components were typically $0.60,0.20$ and $0.15 \mathrm{~m}$ for $M_{2}, S_{2}$ and $N_{2}$ respectively. 


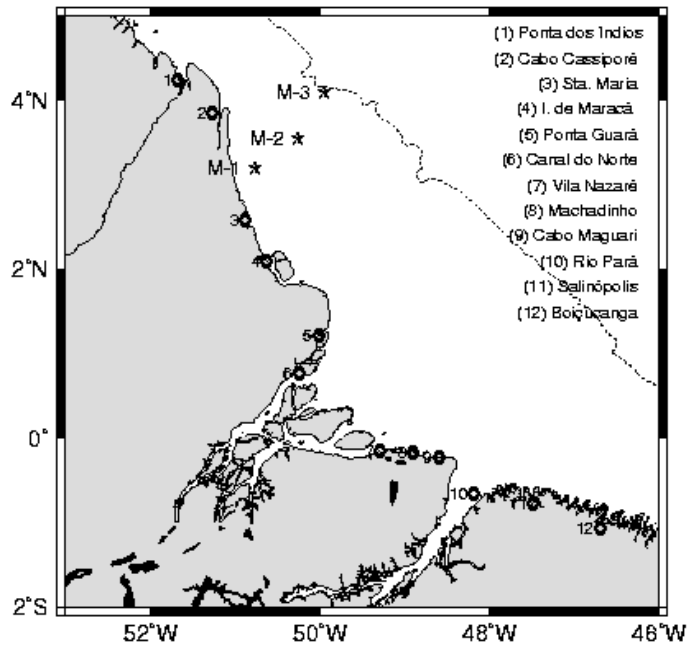

Fig. 4 (1-12) are the tidal stations considered in the AMASSEDS Project, used for model implementation. M1, M2 and M3 are the current-meter mooring locations.

Table 2 Observed results from AMASSEDS and modeled results obtained for $M_{2}$ tidal component. Stations are listed from NW to SE, along-coast oriented (Figure 4).

\begin{tabular}{lcccc} 
& \multicolumn{2}{c}{ Observed } & \multicolumn{2}{c}{ Modeled } \\
Tidal Station & $\begin{array}{c}\text { Amplitude } \\
{[\mathrm{m}]}\end{array}$ & $\begin{array}{c}\text { Phase } \\
{ }^{\circ} G\end{array}$ & $\begin{array}{c}\text { Amplitude } \\
{[\mathrm{m}]}\end{array}$ & $\begin{array}{c}\text { Phase } \\
{ }^{\circ} G\end{array}$ \\
\hline (1)Ponta dos Índios & 1.27 & 288 & 1.43 & 269 \\
(2)Cabo Cassiporé & 1.23 & 288 & 1.43 & 261 \\
(3)Sta. Maria & 2.76 & 301 & 2.65 & 284 \\
(4)Ilha de Maracá & 3.51 & 318 & 3.00 & 317 \\
(5)Ponta Guará & 1.55 & 43 & 1.36 & 0 \\
(6)Canal Norte & 1.55 & 90 & 1.34 & 81 \\
(7)Vila Nazaré & 1.44 & 43 & 1.29 & 29 \\
(8)Machadinho & 1.36 & 12 & 1.37 & 355 \\
(9)Cabo Maguari & 1.23 & 341 & 1.68 & 324 \\
(10)Rio Pará & 1.58 & 344 & 1.99 & 330 \\
(11)Salinópolis & 1.74 & 298 & 2.16 & 281 \\
(12)Boiçucanga & 1.90 & 293 & 2.02 & 293
\end{tabular}

Fortnightly modulation of tides in the interior domain generated amplitudes as high as $2.0 \mathrm{~m}$, during spring tides, and dropt them down to $1.2 \mathrm{~m}$ during neap tides (not shown). This spring-neap tidal modulation is mostly due to $M_{2}$ and $S_{2}$ components and is very important in the positioning of shelf sea fronts over the continental shelf (Sharples and Simpson, 1996) as well as frontal zone positioning over the inner shelf, as seen on Section 5 .

Modeled results for the $M_{2}$ tidal ellipses components were compared with measured results from the AMASSEDS, for moorings M1 M2 and M3, as seen in Figure 5. Table 3 synthesizes these results, as validation of the model skill.
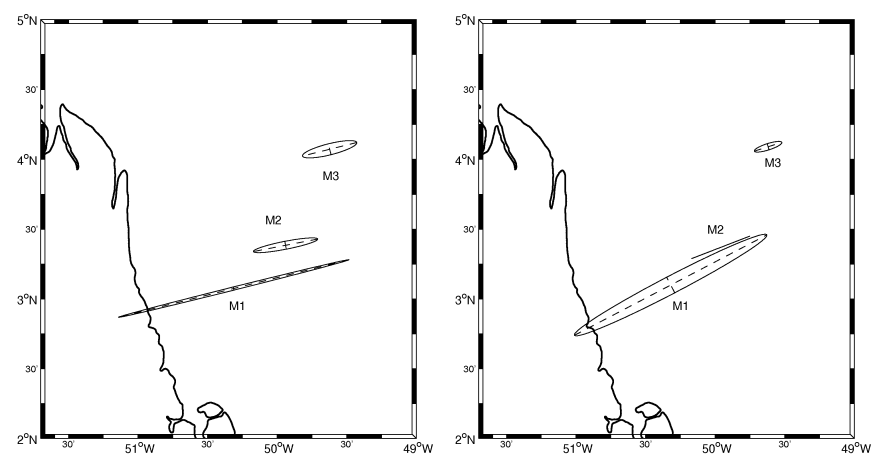

Fig. $\quad 5 \quad M_{2}$ tidal ellipse components considering AMASSEDS moorings M1, M2 and M3 (left panel). Modeled results are represented in the right panel. 
Table 3 Tidal ellipse parameters for the semidiurnal component $M_{2}$ : measured and modeled results for the AMASSEDS mooring locations M1, M2 and M3. $\underline{M}$ and $\underline{m}$ are the semi-major and semi-minor axes. The minus sign in $\underline{m}$ accounts for the counterclockwise ellipse evolution; slope is the orientation of the semi-major axis, North-related. phase is Greenwich related.

\begin{tabular}{|c|c|c|c|c|c|c|}
\hline \multirow{4}{*}{$\begin{array}{l}\text { AMASSEDS } \\
M O D E L\end{array}$} & \multicolumn{6}{|c|}{ Mooring Location } \\
\hline & \multicolumn{2}{|c|}{ M1 } & \multicolumn{2}{|c|}{$\mathrm{M} 2$} & \multicolumn{2}{|c|}{ M3 } \\
\hline & \multicolumn{2}{|c|}{ lon $=50.313 \mathrm{~W} ;$ lat $=3.075 \mathrm{~N}$} & \multicolumn{2}{|c|}{ lon $=49.940 \mathrm{~W} ;$ lat $=3.385 \mathrm{~N}$} & \multicolumn{2}{|c|}{ lon $=49.623 \mathrm{~W} ;$ lat $=4.072 \mathrm{~N}$} \\
\hline & \multicolumn{2}{|c|}{ lon $=50.320 \mathrm{~W} ;$ lat $=3.100 \mathrm{~N}$} & \multicolumn{2}{|c|}{ lon $=49.960 \mathrm{~W} ;$ lat $=3.370 \mathrm{~N}$} & \multicolumn{2}{|c|}{ lon $=49.620 \mathrm{~W} ;$ lat $=4.090 \mathrm{~N}$} \\
\hline & Amass. & Model & Amass & Model & Amass & Model \\
\hline$M\left(m . s^{-1}\right)$ & 1.49 & 1.36 & 0.41 & 0.39 & 0.35 & 0.18 \\
\hline$m\left(m \cdot s^{-1}\right)$ & 0.02 & 0.11 & 0.05 & 0.00 & -0.07 & -0.04 \\
\hline slope. & $149^{\circ}$ & $132.53^{\circ}$ & $146^{\circ}$ & $126.10^{\circ}$ & $149^{\circ}$ & $123.57^{\circ}$ \\
\hline phase & $218^{\circ}$ & $225.41^{\circ}$ & $215^{\circ}$ & $215.50^{\circ}$ & $182^{\circ}$ & $193.98^{\circ}$ \\
\hline
\end{tabular}




\section{Plume dynamics and vertical mixing processes}

Some numerical experiments were conducted to investigate the role of the momentum equation terms on the spreading and fate of the river plume over the AS.The wind stress forcing term acts differently and the plume dynamics are mostly due to the geostrophic degeneration, as first noticed in a numerical study conducted by Paluszkiewicz et al. (1995). Under northwestward wind shifting condition (rare) these authors found this an idealized event, but elucidating. The river plume is quickly trapped south of $5^{\circ} \mathrm{N}$, showing that degeneration acts in order to balance forces into the system. During periods of wind field relaxation, horizontal spreading of the plume occurred nearby the river mouth, because of velocity intensification related to equatorial Kelvin waves. These results are in accordance to Muller-Karger et al. (1988) where the authors investigated a series of satellite imagery and Lagrangian drifter data.

\subsection{Plume spreading on a quiescent shelf}

The first numerical experiment regarding the plume dynamics solely considered the effect of the Amazon River discharge on a quiescent shelf. The purpose of this experiment was to study the model response in absence of the Coriolis term and how this affect the plume dynamics. Temperature, salinity and discharge were held constant, according to typical values for the AS shown in Table 1 In this fashion, only inertial and baroclinic effects were considered in the plume dynamics, and results are mostly due to salinity gradients other than temperature.

In this study, the river plume is defined by a surface frontal zone denoted by the isohaline 24 . Figure 6 shows the plume fate under these conditions, so that it quickly spreads southeastward over the shelf, filling in most of the domain in just 10 days. Also in this condition, the plume largely occupies the domain, denoted by the fact that isohaline 24 occupies most of the AS offshore extension. The plume shape is somewhat round and well developed, once no stirring mechanism acts on it.

Figure 7 shows Lagrangian pathways drawn by neutral buoyancy computational tracers released at the river mouth. After 10 days of simulation, some down-shelf tracers reached up to $46^{\circ} \mathrm{W}$. The absence of tides in this experiment and consequently the inhibition of vertical mixing processes facilitate this spreading pattern.

\subsection{Tidal effect on the plume fate}

The following numerical experiments considered the effect of tides, superimposed on the same river discharge employed in the former experiment. Vertical mixing processes induced by tides affect plume shape and fate, in the sense of promoting plume confinement on the inner shelf (Figures 8 and 9).

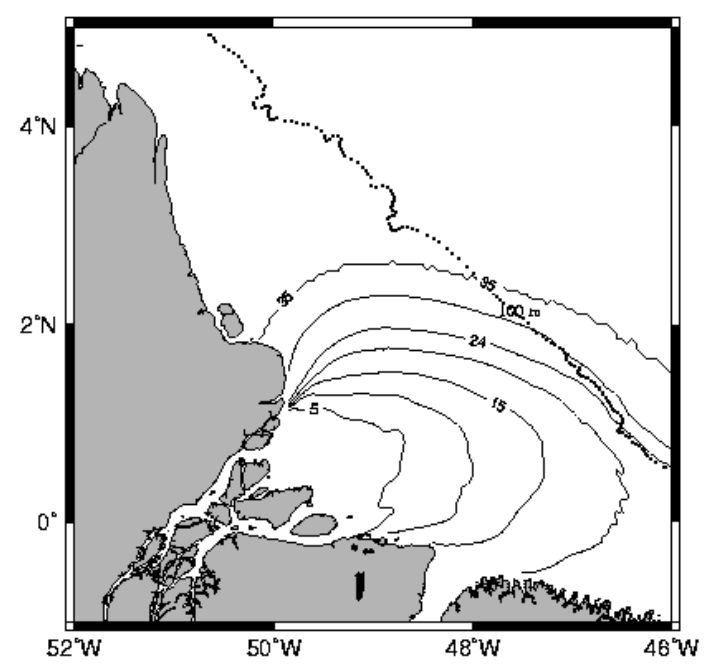

Fig. 6 Horizontal salinity distribution of the Amazon River plume over a quiescent shelf, after 10 days of simulation. Only the river discharge was considered. The line indicates the shelf break.

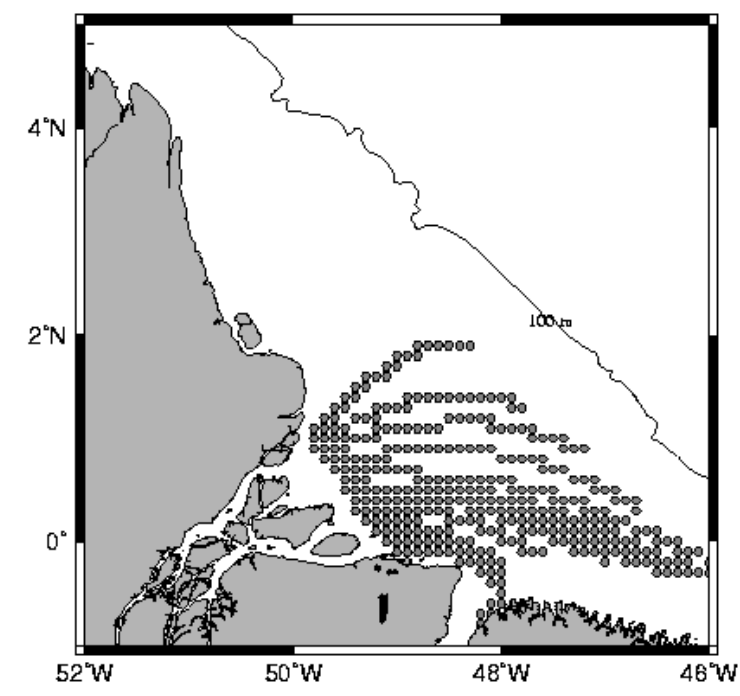

Fig. 7 Computer-generated pathways of Lagrangian tracers spreading over a quiescent shelf, after 10 days of simulation. The line indicates the shelf break.

We notice a sharp reduction in the horizontal plume advection, compared with the spreading experiment over a quiescent shelf. The river waters spread out over the shelf northeastward, mostly driven by inertia rather than buoyancy or other effects. About five days after the start of simulation, the plume turns eastward as a low salinity tongue spreading parallel to $1^{\circ} \mathrm{N}$ until reaching the shelf break, where it is subject of meso- and large-scale oceanic processes. After 15.5 days of simulation, the plume is found well developed over the domain with the isohaline 24 set along the shelf break. The core of plume 


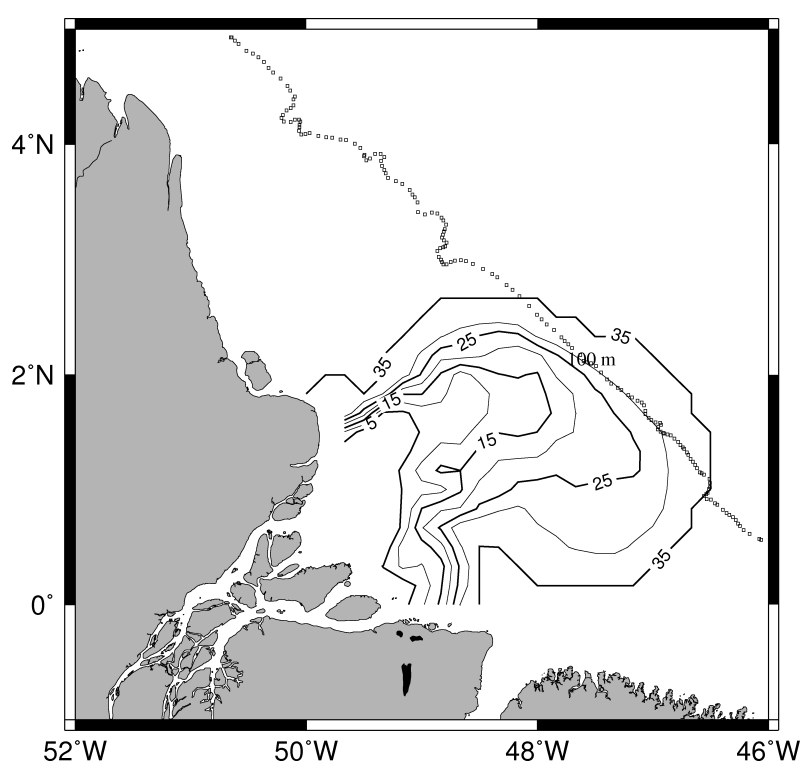

Fig. 8 Horizontal salinity distribution of the Amazon River plume under semi-diurnal tide influences, after 15 days of model initialization. The line indicates the shelf break.

is rough, compared with the round shape seen in the previous experiment, which denotes the occurrence of entrainment processes imposed by intensification of vertical mixing due to tides.

Computational Lagrangian drifters show most of the tracers confined in the river mouth after about 15 days of simulation (Figure 9). This fact denotes the plume confinement mostly imposed by the intense vertical mixing due to tidal currents and shear velocity. Drifters barely reach $47^{\circ} \mathrm{W}$, which is almost $1^{\circ}$ east from where other drifters reached in the former experiment, just after 10 days of simulation (Figure 7).

\subsection{Effect of winds on the plume spreading}

The river discharge and tidal forcing case alone is unrealistic since wind forcing is also important on the AS. Climatology of winds over the AS is mostly dominated by the Inter Tropical Convergence Zone fluctuations (ITCZ), therefore easterly winds prevail and wind-driven circulation follows the shelf orientation towards higher latitudes (Philander, 1990, Castro and Miranda, 1998).

Considering the mean effect of the ITCZ fluctuation along the year, there is a net mass transport towards the northern Hemisphere. Consequently, the along-coast wind component acts northwestward during the whole year, driving sub-diurnal currents on inner and intermediate regions of the continental shelf.

In order to consider the wind stress effect on the plume fate and its horizontal variability, the model was forced with the same river discharge and tidal forcing, as before, but now with a constant wind. The wind field was held constant over the experiment (direction $70^{\circ}$ and magnitude $\left.8.0 \mathrm{~ms}^{-1}\right)$. We chose this extreme ITCZ

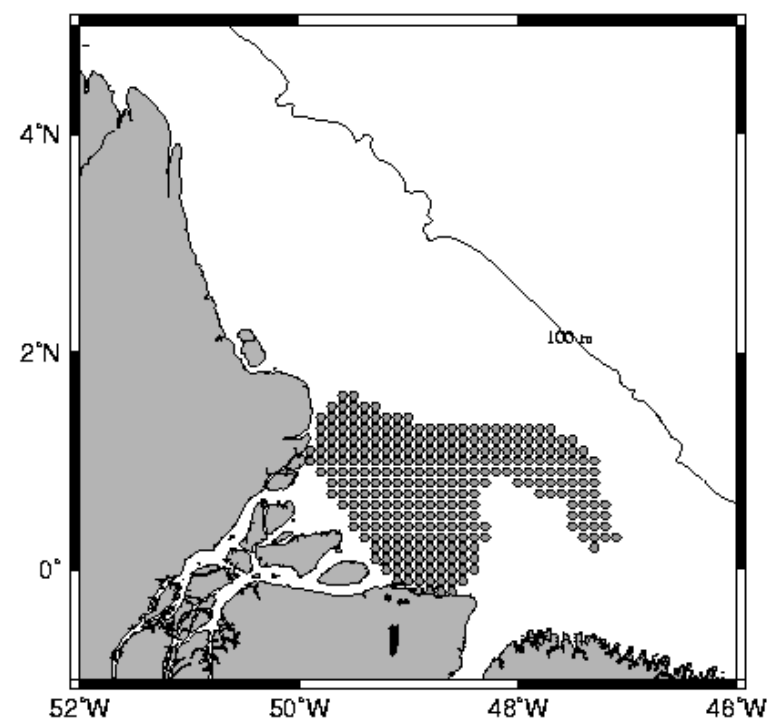

Fig. 9 Computational drifter pathways under semi-diurnal tide influences after 15 days of model initialization. The line indicates the shelf break.

migration from the wind climatology, which occurs during the late summer and beginning of autumn. Wind field in this case represent a situation of plume confinement, causing remarkable effects on the positioning of the surface salinity front. Also, the plume fate in these conditions varies significantly from the previous experiments. Starting from the very beginning of the plume development over the continental shelf, its eastward displacement tendency was blocked, raising the sea level and promoting a strong local pressure gradient.

This effect triggers a northwest pathway for the plume, so that after 15 days of simulation, the river plume occupies the complete central and northern area of the AS (Figure 10). Compared with other experiments, very low salinity waters (less than 5) exhibit a similar pattern near the river mouth. Close to the river mouth, the inertia of the huge discharge appears to overwhelm the wind stress effect on the plume orientation. 


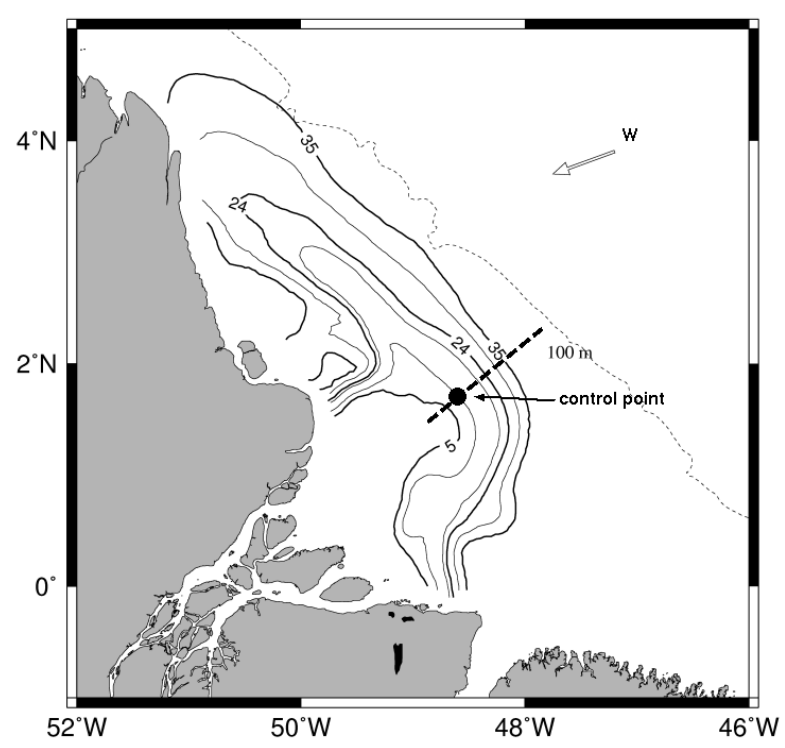

Fig. 10 Amazon River plume under influences of tides, river discharge and easterly wind. Arrow represents wind direction and dashed line indicates the shelf break. Bold dashed line represents the section taken for analysis of the vertical structure.

\section{Frontal Zone Positioning}

In order to investigate the mechanism of generation and maintenance of the frontal zone over the inner shelf, we chose a control point at the computational grid located at the river mouth, nearby the Canal do Norte outflow (North Channel). Our results suggest that the rapid change in bottom slope has a pronounced effect on the vertical structure of the plume, as well as the definition of the frontal zone base (Figure 11).

Indeed, there is a combined effect of the lateral confinement of the river discharge throughout the Canal do Norte and the threshold located in the channel outflow towards the shelf. Analysis of vertical salinity profiles, computed at the threshold, suggest the flux is subject to a kind of hydraulic control once there are sudden rising of isohalines, supported by strong vertical current shear due to inertial discharge (Figure 11).

The Hydraulic Control Theory applied to channels are based on some considerations about the flow, as presence of lateral or bottom constrictions, clear definition of two vertical density layers and the rigid lid approximation on the surface (Chao and Paluszkiewicz, 1991).

The considerations on applying the HCT are not totally satisfied, once the AS is subject to surface displacements caused by tides and also to vertical continuous stratification. We applied the method used in Cudaback and Jay (1996), which explained the dynamics of the Columbia River plume under approximations of the HCT in coastal marine systems.

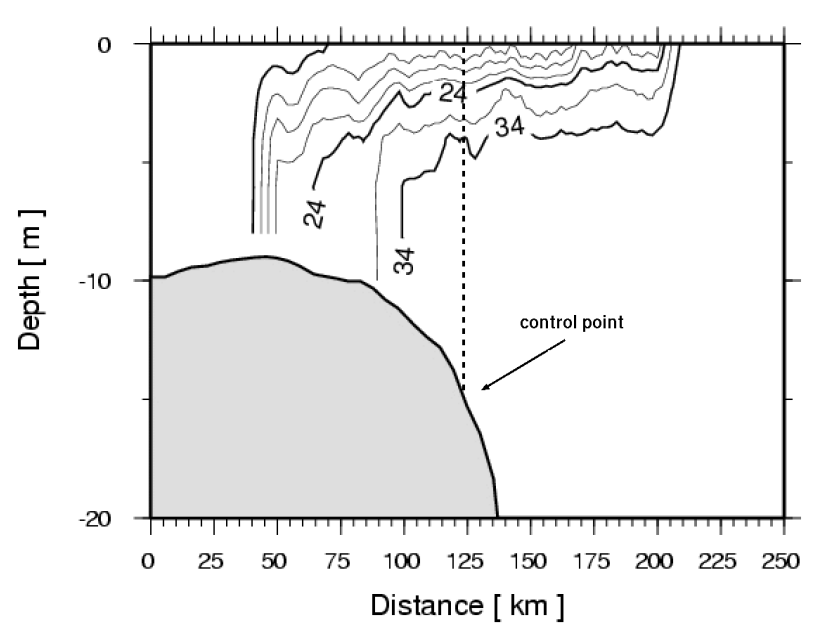

Fig. 11 Salinity modeled profile at the threshold, under influence of tidal vertical mixing. The control point denotes the region where hydraulic jump occurs (also in Figure 10 ).

In the Amazon River case, the low salinity inertial discharge is subject to changes on its dynamical state. According to the $\mathrm{HCT}$, there is a point between the river mouth and the coastal zone where the dynamic condition turns from super-critical to sub-critical. Armi and Farmer (1986) extended the application of HCT by defining an internal, or composite Froud number:

$$
G^{2}=F_{1}^{2}+F_{2}^{2}=\frac{u_{1}^{2}}{g^{\prime} \cdot h_{1}}+\frac{u_{2}^{2}}{g^{\prime} \cdot h_{2}}
$$

where, $g^{\prime}=g\left(\rho_{1}-\rho_{2}\right) / \rho_{1}$ is the reduced gravity; $\rho_{i}$ and $h_{i}$ are density and layer thickness respectively [i=1(top),2(bottom)]; and $F_{i}$ is the Froud number defined in each layer. This composite Froud number was calculated for an outflow cross shelf section at the Canal do Norte (North Channel). The river mouth is located at the shallower section of the AS, as defined in Figures 10 and 11 . The deepest portion of the considered section is located at $87 \mathrm{~m}$ deep, almost at the shelf break and $250 \mathrm{~km}$ from the mouth. The hydraulic control region occurs where the bottom slope is strongest, starting from $-0.125 \mathrm{~m}$ $\mathrm{km}^{-1}$ and reaching up to $-0.385 \mathrm{~m} \mathrm{~km}^{-1}$. The region of maximum gradient in bathymetry occurs at $15 \mathrm{~m}$ deep, around $100 \mathrm{~km}$ from the coast.

\section{Coastal Circulation and River Plume Interactions}

It is remarkable how the Amazon River plume remains distinct over hundreds of kilometers, despite this highly energetic ambient condition with strong fresh water discharge, amplified tides and moderate winds. Its characteristics and shape remain, although one should expect the plume to break up and rapidly vanishes over the AS. The plume remains well formed and confined on its fate 
along the coast, causing a singular dynamic environment mostly related to the buoyancy effect. This situation prevails, nonetheless the progressive distance from the river mouth tends to dissipate these influences. The related coastal transport seems to last long, although there are highly energetic mixing influences such as spring-neap tides and even atmospheric disturbances.

In order to study those facts, we analyzed the vertical stability under extreme tidal conditions, considering fortnightly modulation due to the $M_{2}$ and $S_{2}$ tidal harmonic components. The Richardson number was calculated at the same control point chosen in Section 5 Figure 12 synthesizes the computed results for vertical stability during spring and neap tides. 

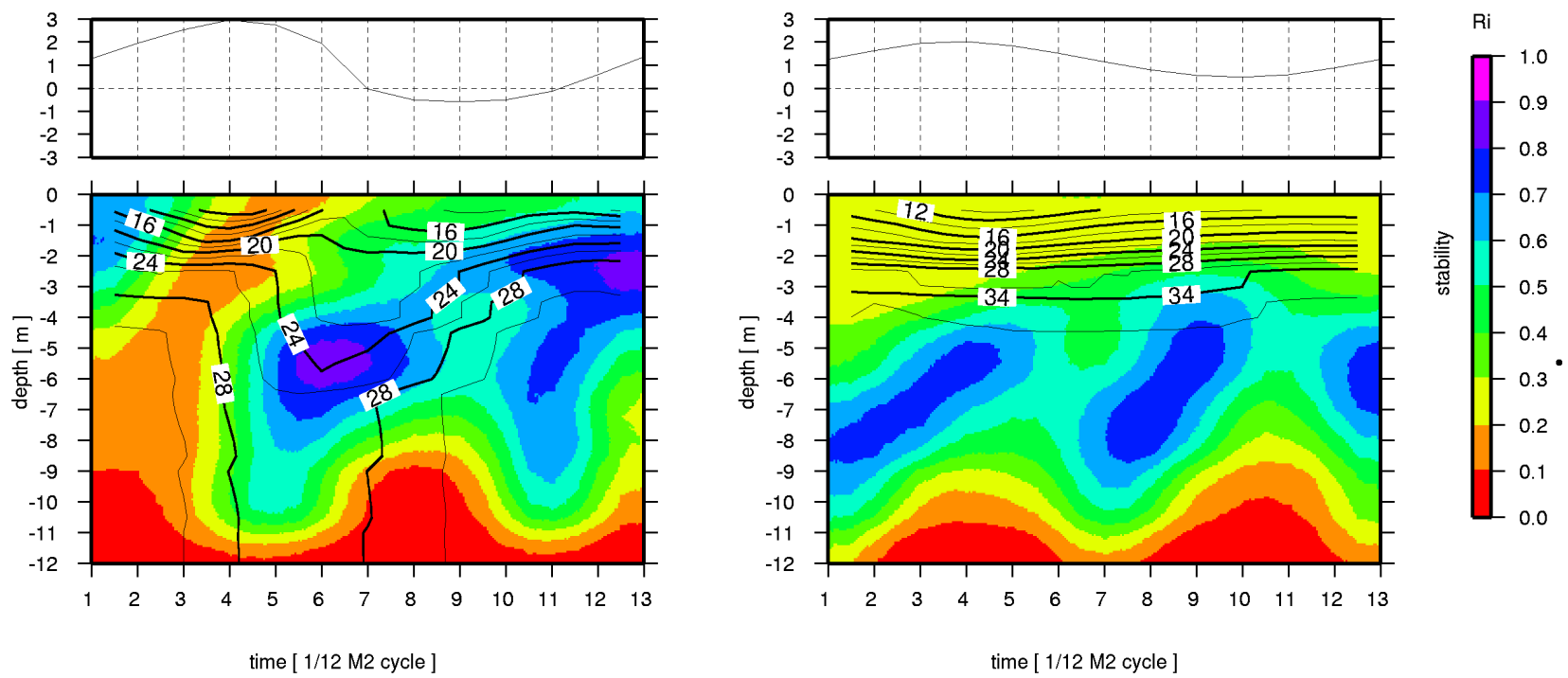

Fig. 12 Diagnosis of vertical stability at the river mouth during spring (left panel) and neap tide (right panel). Richardson number varies over the semidiurnal tidal period. Upper plots represent the offshore current component. 
Sub-critical stability was found on the superficial layer, between 0 and $2 \mathrm{~m}$, at the start of ebb flow $(t=1 \rightarrow$ $\left.2 ; R_{i}>0.30\right)$. Tidal and river flows cause relatively stable surface condition due to low vertical shear.

Stability collapses at depths greater than $4.0 \mathrm{~m}$, mostly related to low stratification, topographic interactions and high shear in the bottom boundary layer. Critical and super-critical conditions are reached from maximum ebb flow $(t=4)$, slowing down after maximum acceleration of ebb flow $(t \approx 6)$, when it remains relatively stable until the next ebb flow period. Intensification of turbulence and the upward shifting in the vertical mixing contribute to the pronounced deepening of the halocline seen in Figure 12 .

Although low stratification acts as a destabilization factor, the relative stability is maintained by means of low vertical shear during low tides. During neap tides, on the other hand, stability is maintained over the entire tidal period in the superficial layer between 0 and $4 \mathrm{~m}$, as seen on Figure 12 p. Stability analysis at the plume genesis location, regarding the hydraulic condition in the Canal do Norte, aims us to explain that remarkable aspect related to the plume distinction over hundreds of kilometers over the AS.

\section{Conclusions}

As seen in other studies, the degree of tidal amplification on coastal regions depends on their resonance characteristics, which relate the basin geometry and the oceanic tides. Through the best model fit, we also found sediment distribution over the AS has some degree on local amplification of currents on the vicinity of fluid mud regions, while current dumps were better fit in regions of coarser sediment patches. Spatial variability of sediments plays an important role in the bottom boundary layer dynamics, once roughness and others physical aspects modify the shear stress parametrization.

The modeled results presented in Table 2 show distinguished tidal amplitudes for coastal stations along the studied area, considering the proper sediment distribution on the coastal zone and basin geometry. Mean differences between modeled and observed tides were 0.34 $\mathrm{m}$ and $26^{\circ}$ for amplitude and phase respectively, considering the 12 tidal stations altogether. Purging the Maracá Island Station, mean differences dropt to 0.30 $\mathrm{m}$ and $22^{\circ}$ respectively, indicating that local effects are not totally resolved from the model scale. The coastal channel between the Maracá Island and the continent must somehow act as accelerating the tidal currents and amplifying them locally. The remarkable result involving tides on this study was its combined influences with the $\mathrm{HCT}$, on definition of the frontal zone positioning over the inner AS.

We studied the salinity front formation and maintenance from results of the Hydraulic Control Theory applied to the AS and analysis of vertical structure and mixing properties. From those assumptions, we were able to study the frontal zone positioning over the shelf and how tidal currents and low salinity inertial flow behave against bathymetric nuances. The strong vertical shear due to tides and the inertial discharge suffice to explain some degree of homogenization found on waters that leaves the river mouth. Through its way offshore, bottom slope topography generates a kind of hydraulic jump at some point in the estuary threshold, separating the plume from the bottom. From that point, the lower salinity waters run over the shelf mostly disconnected from bathymetric effects. This combined effect of tidal mixing and hydraulic jump defines the frontal zone positioning over the AS.

In a numerical experiment we idealized a continental shelf in the absence of wind and other remote forces (Figure 8). Considering local influences (i.e., inertial river discharge, stratification and tides), we were able to focus on the plume genesis aspects. Leaving the mouth, the Amazon River plume tends to propagate offshore (eastward) due to high momentum flux, but rapidly acquiring negative vorticity by compression of the hyposaline layer, turning southeastward. Once at the equator, geostrophy effect vanishes and that initial tendency on turning the plume clockwise also disappears, partially due to lateral constriction imposed by the coast, as seen in Figure 8. Starting at the point where the river discharges into the shelf, the control point defines where the fluid gains negative vorticity. Downstream of the hydraulic jump, the plume spreads southeastward (negative-vorticity related), limiting the extension of the salinity front nearby the shelf break. A numerical experiment with local wind forcing added produces a more realistic dynamic condition. As the local wind field is predominantly eastward, even moderate winds are capable of generating enough circulation to drive away the plume, and overwhelms that negative vorticity effect.

\section{References}

Adams, C. E. and G. L. Weatherly (1981). Some effects of suspended sediment stratification on an oceanic bottom boundary layer. J. geophys. Res. (86), 41614172 .

Alessi, C., S. J. Lentz, R. C. Beardsley, B. M. Castro, and W. R. Geyer (1992, September). A multidisciplinary amazon shelf sediment study (amasseds): Physical oceanography moored array component. Technical Report WHOI-92-36, Woods Hole Oceanography Institution.

AMASSedS (1990). A multi-disciplinary amazon shelf sediment study (amasseds). Eos, Trans. AGU, 71, 1771.

Armi, L. and D. M. Farmer (1986). Maximal two-layer exchange through a contraction with barotropic net flow. J. Fluid Mech. 164, 27-51. 
Beardsley, R. C., J. Candela, R. Limeburner, W. R. Geyer, S. J. Lentz, B. M. Castro, D. Cacchione, and N. Carneiro (1995, february). The $\mathrm{m} 2$ tide in the amazon shelf. J. geophys. Res. $100(\mathrm{C} 2)$, 2283-2319.

Blumberg, A. F. (1996). An estuarine and coastal ocean version of pom. In Proceedings of the Princeton Ocean Model Users Meeting (POM96).

Blumberg, A. F. and G. L. Mellor (1980, August). A coastal ocean numerical model. In J. Sundermann and K. P. Holz (Eds.), Mathematical Modelling of Estuarine Physics, Proceedings of an International Symposium, Berlin. Spring-Verlag.

Blumberg, A. F. and G. L. Mellor (1987). A description of a three-dimensional coastal ocean circulation model. In N. Heaps (Ed.), Mathematical Modelling Three-Dimensional Coastal Ocean Models, Berlin, pp. 1-16. American Geophysical Union.

BRASIL (1979). Margem continental norte: Mapa faciológico dos sedimentos superficiais da plataforma e da sedimentação quaternária no oceano profundo. mapa cartográfico - escala 1:3.500.000. Projeto REMAC - Reconhecimento Global da Margem Continental Brasileira.

Castro, B. M. and L. B. Miranda (1998). The Sea, Volume 11, Chapter Physical Oceanography of the Western Atlantic Continental Shelf located between $4^{\circ} \mathrm{N}$ and $34^{\circ} \mathrm{S}$, pp. 209-251. John Wiley \& Sons.

Chao, S.-Y. and T. Paluszkiewicz (1991, abril). The hydraulics of density currents over estuarine sills. J. Geophys. Res. 96(C4), 7065-7076.

Cudaback, C. N. and D. A. Jay (1996). Formation of columbia river plume: Hydraulic control in action? In D. G. Aubrey and C. T. Friedrichs (Eds.), Buoyance Effects on Coastal and Estuarine Dynamics, Volume 53 of Coastal and Estuarine Studies, Washington, DC, pp. 139-174. American Geophysical Union.

Dyer, K. R. (1986). Coastal and estuarine sediment $d y$ namics. Great Britain: John Wiley and Sons Ltd.

Eanes, R. and S. Bettadpur (1995, December). The csr 3.0 global ocean tide model. Technical Report CSRTM-95-06, Center for Space Research.

Fontes, R. F. C. (2000). Modelagem Numérica da Circulação na Plataforma Continental Amazônica. Ph. D. thesis, Instituto Oceanográfico, São Paulo, Brasil.

Gabioux, M., S. B. Vinzon, and A. M. Paiva (2005). Tidal propagation over fluid mud layers on the amazon shelf. Continental Shelf Research (25), 113-125.

Geyer, W. R., R. C. Beardsley, S. J. Lentz, J. Candela, R. Limeburner, W. E. Johns, B. M. Castro, and I. D. Soares (1996). Physical oceanography of the amazon shelf. Continent. Shelf Res. 5/6(16), 575-616.

Glen, S. M. and W. D. Grant (1987). A suspended sediment stratification correction with rough bottom. $J$. geophys. Res. 92, 8244-8464.

Grant, W. D. and O. S. Madsen (1986). The continentalshelf bottom boundary layer. Ann. Rev. Fluid Mech. 18, 265-305.
Heathershaw, A. D. (1979). The turbulent structure of the bottom boundary layer in a tidal current. Geophys. J. Astron. Soc. 58, 395-430.

Johns, W. E., T. N. Lee, R. C. Beardsley, J. Candela, R. Limeburner, and B. M. Castro (1998). Annual cycle and variability of the north brazil current. J. phys. Oceanogr. 28, 103-128.

Johns, W. E., T. N. Lee, F. Schott, R. J. Zantopp, and R. H. Evans (1990). The north brazil current retroflection: seasonal structure and eddy variability. J. geophys. Res. (95), 22103-22120.

Mellor, G. and T. Yamada (1982). Development of a turbulence closure model for geophysical fluid problems. Revs. Geophys. Space Phys. (20), 851-875.

Mellor, G. L. and L. H. Kantha (1985). Open boundary condition for circulation models. J. hydraul. Engng., Am. Soc. civ. Engrs (111), 237-255.

Miranda, L. B., B. M. Castro, and B. Kjefve (2002). Principios de Oceanografia Fisica de Estuarios. Edusp.

Muller-Karger, F. E., M. C. R., and R. P. L. (1988, May). The dispersal of the amazon's water. $\mathrm{Na}$ ture 333(6168), 56-59.

Nikiema, O., J.-L. Devenon, and M. Baklouti (2007). Numerical modeling of the amazon river plume. Continental Shelf Research (27).

Paluszkiewicz, T., T. B. Curtin, and S. Chao (1995). Wind-driven variability of the amazon river plume on the continental shelf during the peak outflow season. Geo-Marine Letts 15, 179-184.

Philander, S. G. (1990). El Niño, La Niña and the Southern Oscillation, Volume 46 of International Geophysics Series. San Diego, EUA: Academic Press.

Sharples, J. and J. H. Simpson (1996). The influence of the springs-neaps cycle on the position of shelf sea fronts. In D. G. Aubrey and C. T. Friedrichs (Eds.), Buoyance Effects on Coastal and Estuarine Dynamics, Volume 53 of Coastal and Estuarine Studies, Washington, DC, pp. 71-82. American Geophysical Union.

Taylor, P. A. and K. R. Dyer (1977). Theoretical models of flow near the bed and their implications for sediment transport. In E. D. Goldberg, I. N. McCave, J. J. O'Brien, and J. Steele (Eds.), The Sea, Volume 6, pp. 579-601. New York: Wiley-Interscience. 